\title{
Lymphedema: a mini-review on the pathophysiology, diagnosis and treatment
}

\author{
Haitham Shoman*1 and Samer Ellahham ${ }^{1}$ \\ ${ }^{1}$ Cleveland Clinic Foundation, Ohio, USA and Sheikh Khalifa Medical City managed by Cleveland Clinic, Abu Dhabi, UAE
}

\begin{abstract}
Lymphedema is a complex chronic debilitating condition resulting from inadequate lymph flow leading to significant physical and psychological morbidity. Recent studies of lymphedema diagnosis and therapy are promising. The bedside diagnosis of lymphedema requires high level of suspicion and identification of specific findings on physical examination. Noninvasive diagnostic tools are helpful in confirming the diagnosis. Treatment with decongestive lymphatic therapy provides improvement in patient symptoms and volume reduction. This mini-review article highlights the pathophysiology, diagnosis and treatment of lymphedema.
\end{abstract}

\begin{abstract}
Abbreviations: CAM: Complementary and Alternative Medicine; CB: Compression bandaging; CDT: Complete Decongestive Therapy; CG: Compression garments; CT: Computed tomography; IPC: Intermittent Pneumatic Compression; LE: Lymphedema; MLD: Manual lymphatic drainage; MRI: Magnetic resonance imaging; US: Ultrasound
\end{abstract}

\section{Introduction}

Lymphedema (LE) is a complex edematous condition that occurs when tissue homeostasis is jeopardized due to insufficient lymph transport [1]. It is characterized by the accumulation of regional interstitial protein-rich fluid [2]. Lymphedema is either primary or secondary. Primary lymphedema is classified according to the age when edema appeared. Congenital lymphedema occurs at birth and is apparent at two years of life. Lymphedema praecox occurs at puberty and lymphedema tarda is seen at those above the age of 35 years. Secondary lymphedema results from disease processes, post-surgery and axillary node clearance and after radiotherapy and irradiation. It is sometimes confused with filariasis.

\section{Pathophysiology}

LE is considered as the pathologic outcome of inadequate lymphatic outflow. Lymphatic aplasia, hypoplasia, valvular insufficiency, obliteration/disruption of lymphatic vessels and primary decreased lymphatic contractility are all direct causes of the pathology [3]. This leads to lymphatic hypertension and decreased contractility of lymph. As a result lymphostatis and accumulation of lymph, interstitial fluid, proteins and glycosaminoglycans takes place within the skin and subcutaneous tissue. This eventually stimulates collagen production by fibroblasts, disruption of elastic fibers, and activation of keratinocytes, fibroblasts and adipocytes where skin thickening and subcutaneous tissue fibrosis is the result [3-5]. Studies have shown that stasis of lymph causes accumulation of protein and cellular metabolites in the extracellular space that raises the tissue colloid osmotic pressure, causing water accumulation, formation of edema and increased interstitial hydraulic pressure [4,5].

\section{Diagnosis}

A LE patient presents with a full or heavy feeling with a tight skin feeling of a limb or genitals. In the affected limb, there will be less movement or flexibility in hands, wrists or ankle. The patients can also encounter trouble in fitting into clothing or jewelry in one specific area as a jacket sleeve being tight or difficulty wearing the trousers or shoes.

LE has to be correctly diagnosed for proper treatment. True LE is due to a swelling caused by the abnormality of the lymphatic system and it may occur with other diseases. Some diagnostic tests for LE include [6]:

1) History and physical examination has to be done with an experienced physician [7];2) Soft tissue imaging by magnetic resonance imaging (MRI), computed tomography (CT) and some types of ultrasound (US) to detect extra fluid in tissues [8]; 3) Lymph vessel and lymph node imaging by Lymphoscintigraphy to detect abnormalities in the lymphatic system. Technetium and Sulphur colloid are the radio-labelled particles of protein that are injected under the skin to be examined [9]; 4) Measures of volume are used to quantify the presence and severity of LE and the response to treatment. This is done by tape measurements, perometry or water displacement [10]; 5) Changes in electrical conductance is done using the Bioimpedance Spectroscopy (BIS) where an electric current passes through the limb and the resistance is measured [11]. 6) Changes in biomechanical properties of tissues (skin and subcutaneous tissue) are measures using the tissue dielectric constant and tonometry [12]; 7) Genetic testing specially for primary LE since this will help identify chromosomal abnormalities such as in Turner's syndrome and Milroy's disease [13,14]; 8) Other vascular imaging such as echocardiogram, venous ultrasound and arterial ultrasound with ankle brachial index (ABI) are used for secondary edemas resulting from abnormalities in the cardiovascular system for instance [6].

Correspondence to: Haitham Shoman, MBBS, DIC, Dip, MPH, Cleveland Clinic Foundation, Ohio, USA and Sheikh Khalifa Medical City managed by Cleveland Clinic, Abu Dhabi, UAE, E-mail: haitham.sh89@gmail.com

Key words: lymphedema, compression, fluid, lymph, lymphatic system

Received: March 24, 2017; Accepted: April 12, 2017; Published: April 15, 2017 


\section{Treatment}

LE can be treated in various ways. The Complete Decongestive Therapy (CDT) has been widely known and implemented in the treatment of LE and specifically post cancer related LE [15]. According to the Medicare Evidence Development and Coverage Development Committee, CDT includes 1) manual lymphatic drainage (MLD); 2) compression bandaging (CB) and/or garments (CG); 3) exercise; 4) skin care; and 5) sequential pumps [16]. The American LE Framework Project also showed that CDT is an effective intervention in reducing LE [17,18]. After CDT, self-maintenance is crucial involving selfMLD, day-time CG, CB, night-time exercise, skin care and nutrition [6]. To achieve this, patient education and awareness regarding LE management modalities is important including hygiene, moisturizing, sunscreen, avoidance of blood flow constriction and use of tourniquet [6]. Manual lymphatic drainage (MLD) is a massaging technique that enables the sequestration and lymph transport. The congested lymph moves from the restricted locations to the patent and intact nodal basins. Experts also recommend the use of $\mathrm{CB}$ during exercise [6]. Exercise should be tailored to the patient's physical condition and abilities. In conclusion, CDT, MLD and CB controls symptoms and improves the quality of life for LE patients [15].

Surgical treatment for LE includes excisional/debulking, lymphatic reconstruction, or tissue transfer [19]. Excisional procedures involve removing the fibrofatty tissue that has formed secondary to sustained lymphatic fluid stasis [15]. Procedures include debulking, liposuction, and amputation are considered an option when standard LE treatment, such as CDT, has failed [15]. Studies have shown that excisional procedures had the highest LE volume loss (91.1\%) compared to lymphatic reconstruction (52.9\%) and tissue transfer (45.6\%) [19]. It is worth noting that the majority of the procedures will be followed up with lifelong CG to preserve post-operative results [19].

Intermittent Pneumatic Compression (IPC) Therapy is well tolerated in low to moderate pressures and studies show that they may be part of a supervised multi-modality approach for home based patients with LE [20].

Complementary and Alternative Medicine (CAM) has been adopted as a means for LE management where patients practice mindfulness-based stress reduction and studies showed that it improves the quality of life and reduces psychological distress [21]. There is also a higher patients' adherence rate with CAM and aqua lymphatic therapy [22]. Yoga, acupuncture/moxibustion, and Tai Chi breathing with arm exercises were shown to be safe by pilot data, but still more studies are needed to understand their role in LE management [23].

\section{Conclusion}

Lymphedema is a chronic condition that occurs due to insufficient lymph flow leading to limbs or genitals swelling. It is important to properly diagnose LE to understand the extent and severity of extra fluid to tailor treatment accordingly. There are several diagnostic tools available and each has a specific method of implementation. LE is classified in general into primary or secondary. The treatment of lymphedema varies from complete decongestive therapy, surgery, pneumatic compression to complementary and alternative medicine.

\section{Declaration}

The authors declare no financial support was sought in this project and they declare no conflicts of interest.

\section{References}

1. Rockson SG, Rivera KK (2008) Estimating the population burden of lymphedema. Ann N Y Acad Sci 1131: 147-154. [Crossref]

2. Rockson SG (2001) Lymphedema. Am J Med 110: 288-295. [Crossref]

3. Szuba A, Rockson SG (1997) Lymphedema: anatomy, physiology and pathogenesis Vasc Med 2: 321-326. [Crossref]

4. Wiederhielm C, Weston B (1973) Microvascular, lymphatic, and tissue pressures in the unanesthetized mammal. Am J Physiol 225: 992-996. [Crossref]

5. Bates DO, Levick JR, Mortimer PS (1992) Subcutaneous interstitial fluid pressure and arm volume in lymphoedema. Int J Microcirc Clin Exp 11: 359-373.

6. NLN Medical Advisory Committee (2011) TOPIC: The diagnosis and treatment of lymphedema. Natl Lymphedema Netw Available at:http://www.lymphnet.org/pdfDocs/ nlntreatment.pdf[Accessed 14 February 2011].

7. Bernas MJ, Askew RL, Armer JM, Cormier JN (2010) Lymphedema: how do we diagnose and reduce the risk of this dreaded complication of breast cancer treatment? Curr Breast Cancer Rep 2: 53-58.

8. Astrom KGO, Abdsaleh S, Brenning GC, Ahlstrom KH (2001) MR imaging of primary, secondary, and mixed forms of lymphedema. Acta radiol 42: 409-416. [Crossref]

9. Szuba A, Razavi M, Rockson SG (2002) Diagnosis and treatment of concomitant venous obstruction in patients with secondary lymphedema. J Vasc Interv Radiol 3: 799-803. [Crossref]

10. Unno N, Nishiyama M, Suzuki M, et al. (2008) Quantitative lymph imaging for assessment of lymph function using indocyanine green fluorescence lymphography. Eur J Vasc Endovasc Surg 36: 230-236. [Crossref]

11. Rockson S (2007) Bioimpedance analysis in the assessment of lymphoedema diagnosis and management. J Lymphoedema 2: 44-48.

12. Ridner S, Montgomery L, Hepworth J, Stewart B, Armer JM (2007) Comparison of upper limb volume measurement techniques and arm symptoms between healthy volunteers and individuals with known lymphedema. Lymphology 40: 35-46. [Crossref]

13. Connell FC, Ostergaard P, Carver C, Brice G, Williams N, Mansour S, et al. (2009) Analysis of the coding regions of VEGFR 3 and VEGFC in Milroy disease and other primary lymphoedemas. Hum Genet 124: 625-631. [Crossref]

14. Ferrell RE, Kimak MA, Lawrence EC, Finegold DN (2008) Candidate gene analysis in primary lymphedema. Lymphat Res Biol 6: 69-76. [Crossref]

15. Armer JM, Hulett JM, Bernas M, Ostby P, Stewart BR, Cormier JN, et al. (2013) Best practice guidelines in assessment, risk reduction, management, and surveillance for post-breast cancer lymphedema HHS public access. Curr Breast Cancer Rep 5: 134 144. [Crossref]

16. Moseley AM, Sherrington C, Elkins MR, Herbert RD, Maher CG (2009) Indexing of randomised controlled trials of physiotherapy interventions: a comparison of AMED, CENTRAL, CINAHL, EMBASE, Hooked on Evidence, PEDro, PsycINFO and PubMed. Physiotherapy 95: 151-156. [Crossref]

17. Lasinski BB, Thrift KM, Squire D, Austin MK, Smith KM, Wanchai A, et al. (2012) A systematic review of the evidence for complete decongestive therapy in the treatment of lymphedema from 2004 to 2011. PM R 4: 580-601. [Crossref]

18. Armer JM, Stewart BR, Wanchai A, Lasinski BB, Smith KM, Cormier JN (2012) Rehabilitation concepts among aging survivors living with and at risk for lymphedema. Top Geriatr Rehabil 28: 260-268.

19. Cormier JN, Rourke L, Crosby M, Chang D, Armer J (2012) The surgical treatment of lymphedema: a systematic review of the contemporary literature (2004-2010). Ann Surg Oncol 19: 642-651. [Crossref]

20. Feldman JL, Stout NL, Wanchai A, Stewart BR, Cormier JN, Armer JM (2012) Intermitten pneumatic compression therapy: a systematic review. Lymphology 45: 13-25. [Crossref]

21. Matchim Y, Armer JM, Stewart BR (2011) Effects of mindfulness-based stress reduction (MBSR) on health among breast cancer survivors. West J Nurs Res 33: 996-1016. [Crossref]

22. Tidhar D, Katz-Leurer M (2010) Aqua lymphatic therapy in women who suffer from breast cancer treatment-related lymphedema: a randomized controlled study. Support Care Cancer 18: 383-392. [Crossref]

23. Witt CM, Pach D, Brinkhaus B, Wruck K, Tag B, Mank S, et al. (2009) Safety of acupuncture: results of a prospective observational study with 229,230 patients and introduction of a medical information and consent form. Forsch Komplementmed 16: 91-97. [Crossref]

Copyright: (C2017 Shoman H. This is an open-access article distributed under the terms of the Creative Commons Attribution License, which permits unrestricted use, distribution, and reproduction in any medium, provided the original author and source are credited. 